\title{
Muscular dystrophy: Experimental animal models and therapeutic approaches (Review)
}

\author{
GISELA GAINA $^{1,2^{*}}$ and ALEXANDRA POPA (GRUIANU) $)^{1,3 *}$ \\ ${ }^{1}$ Laboratory of Cell Biology, Neuroscience and Experimental Myology, 'Victor Babes' National Institute of Pathology, \\ 050096 Bucharest; ${ }^{2}$ Department of Biochemistry and Molecular Biology, University of Bucharest, \\ 050095 Bucharest; ${ }^{3}$ Department of Animal Production and Public Health, University of Agronomic \\ Sciences and Veterinary Medicine of Bucharest, 050097 Bucharest, Romania
}

Received September 18, 2020; Accepted October 19, 2020

DOI: $10.3892 / \mathrm{etm} .2021 .10042$

\begin{abstract}
The muscular dystrophies are a heterogeneous group of genetically inherited diseases characterized by muscle weakness and progressive wasting, which can cause premature death in severe forms. Although $>30$ years have passed since the identification of the first protein involved in a type of muscular dystrophy, there is no effective treatment for these disabling disorders. In the last decade, several novel therapeutic approaches have been developed and investigated as promising therapeutic approaches aimed to ameliorate the dystrophic phenotype either by restoring dystrophin expression or by compensating for dystrophin deficiency. Concurrently, with the development of therapeutic approaches, in addition to naturally occurring animal models, a wide range of genetically engineered animal models has been generated. The use of animals as models of muscular dystrophies has greatly improved the understanding of the pathogenicity of these diseases and has proven useful in gene therapy studies. In this review, we summarize these latest innovative therapeutic approaches to muscular dystrophies and the usefulness of the various most common experimental animal models.
\end{abstract}

\section{Contents}

1. Introduction

2. Requirements for a well-developed animal model

3. Animal models for dystrophinopathy

Correspondence to: Dr Gisela Gaina, Laboratory of Cell Biology, Neuroscience and Experimental Myology, 'Victor Babes' National Institute of Pathology, Splaiul Independentei 99-101, 050096 Bucharest, Romania

E-mail: giselagaina@yahoo.com

${ }^{*}$ Contributed equally

Key words: muscular dystrophy, animal models, gene therapy, $m d x$ mouse, canine model, pig model, read-through, exon skipping
4. Therapeutic strategies in DMD animal models

5. Therapies aimed to restore dystrophin expression

6. Therapies aimed to compensate for the lack of dystrophin

7. Animal models for other types of muscular dystrophies

8. Ethical concerns and animal models

9. Conclusions

\section{Introduction}

Muscular dystrophies (MD) refer to a group of inherited heterogeneous muscle diseases characterized by skeletal muscle degeneration and weakness (1) that progress to severe physical disability and various complications.

Since the identification in 1987 (2) of the first protein involved in a type of muscular dystrophy, dystrophin, numerous other dystrophin-associated proteins have been identified in skeletal muscle. These proteins form a plasma membrane transmembrane complex named the dystrophin-glycoprotein complex (DGC) (3), which links the extracellular matrix to the subsarcolemmal cytoskeleton (4). To date, the DGC in skeletal muscle is formed by transmembrane, cytoplasmic, and extracellular proteins such as dystrophin, the sarcoglycan complex $(\alpha-, \beta-, \gamma$ - and $\delta$-sarcoglycan), the dystroglycan complex ( $\alpha$ - and $\beta$-dystroglycan), sarcospan and, $\alpha$ - and $\beta$-syntrophins. This complex along with extra- and intracellular proteins [nitric oxide synthase (nNOS), dystrobrevin, caveolin 3] plays an important role in the mechanical stability of the plasma membrane and protects muscle fibers from damage during contraction (5). The mutations that occur in the genes that encode for all these proteins are responsible for the occurrences of different types of muscular dystrophies (6). To date, $>30$ types of muscular dystrophy with a wide range of clinical manifestation, different age of onset, the pattern of inheritance, and life expectancy have been identified (1). These vary from severe forms such as Duchenne muscular dystrophy (DMD) with early childhood-onset and early death, to forms with a later onset that do not affect lifespan such as limb-girdle muscular dystrophy (LGMD) (7). The main and most studied types of muscular dystrophy are Duchenne and Becker muscular dystrophy (BMD), LGMD, congenital muscular dystrophy (CMD), and Emery-Dreifuss muscular dystrophy (EDMD) (8). 
Despite extensive discoveries over the years and the improvement in the understanding of the molecular basis of the muscular dystrophies (9), currently, there is no cure or treatment for these conditions. Identification of genetic defects specific to each type of muscular dystrophy as well as biochemical changes of proteins, have provided essential information concerning the pathophysiology of muscle diseases and paved the way to create appropriate animal models for the study of these diseases.

Numerous animal models have been developed and used to prevent disease progression in biomedical research $(10,11)$. In addition, animal models have been used for amelioration of muscle-associated disorders in regenerative medicine studies (12), for a better understanding of the physiological mechanism of the diseases as well as for the developing and testing of potential therapeutic strategies.

The development of therapy is the main concern of researchers worldwide and for this purpose, numerous studies have been conducted on animal models (13-17). Over the years, developed animal model systems are frequently used in different experiments and play a central role in research (17-20). To date, they have demonstrated, their usefulness in pre-clinical studies on the safety and efficacy of different therapeutic approaches. In addition, for the understanding of the pathogenesis of these disorders, mutant animal models have been demonstrated to be an essential tool and provide valuable insights in deciphering the underlying mechanisms of these conditions $(14,21,22)$.

Different types of animal models for muscular dystrophies such as mouse, pig, rabbit, dog, hamster, and sheep have been developed to study the different pathogenetic mechanisms of muscle fiber, histopathological changes, necrosis and myogenesis, inflammatory processes in the muscle, muscle fibrosis, disease progression as well as the effectiveness of new drugs (15,23-27). However, all developed animal models still do not fully reflect human pathology, and therefore, their constant improvement over time has been and is a necessity. However, the mouse remains the most widely used animal model for the study of muscular dystrophies.

The aim of the present study was to explore the most used animal models of muscular dystrophy, and how these models contributed to the understanding of the disease and to the muscular dystrophy therapeutic approaches to date.

\section{Requirements for a well-developed animal model}

It is well known that a disease induced artificially in an animal does not recapitulate identical conditions that occur naturally in humans. However, animals are widely used in scientific experiments due to genetics, anatomy, and physiology similarities with humans. The most common species used in experiments for muscular dystrophy studies are mice, dogs, pigs, Drosophila, and zebrafish. Genetic diseases (e.g., muscular dystrophies) occur naturally in some species whereas, in others they must be genetically induced. In experimental research, both types of animals are used for identification of the disease-causing gene as well as genetic inheritance pattern, to understand the cellular and molecular mechanisms underlying genetic disease, and its treatment $(28,29)$.
To obtain significant valid results, these experiments involve the use of a large number of laboratory animals. For this reason, the animal used for experiments should be easy to acquire at a reasonable cost and have a low maintenance cost. It is also desirable, that the animals used in experiments should be easy to handle and have a high reproductive rate (12). The use of laboratory animals also involves the participation of veterinarians in scientific experiments which will contribute to maintaining animal health. Their knowledge and skills in animal anatomy, physiology, and pathology as well as internal medicine, and surgery contributes to the success of a scientific experiment (30).

In order to be able to provide the best predictive data and to obtain valuable information in understanding the pathogenic mechanisms in different diseases, for an appropriate disease model a number of factors should be considered (31): i) Adequately designed and conducted, ii) well-defined genetic characteristics, iii) mimic aspects of a disease or pathological condition found in humans as closely as possible and iv) reproducibility. The conditions of the experiment are important; they must be strictly monitored throughout their development. In addition, a thorough understanding of the limitations of animal models, differences, and similarities between animals and humans, contributes to the avoidance of misinterpretations of results when data obtained are extrapolated from animal to human and positively influence the success of an experiment (32).

An ideal animal model of muscular dystrophy should resemble human muscle structure, express the key aspects of the disease, and have similar gene expression patterns of human disorders. All these aspects are not found in a single animal model requiring the use of several animal models to mimic human disease. Therefore, it must be borne in mind that the animal model must provide insights into the mechanisms of the disease and should be adequate for studying a particular hypothesis (33).

Knowledge thus far of $>30$ different types of muscular dystrophy each with specific features has led to the improvement of animal study models for each type of muscular dystrophy. However, each model has its advantages and limitations.

\section{Animal models for dystrophinopathy}

Due to the large number of genes that are involved in muscular dystrophies numerous animal models have been developed over time.

Duchenne and Becker muscular dystrophies (dystrophinopathies) the most common forms of muscular dystrophy are $\mathrm{X}$-linked allelic muscle diseases that vary between them in the age of onset, the severity of manifestation, and life expectancy. Both are caused by the mutations in the dystrophin gene (DMD) which encodes for a structural protein called dystrophin with an important role in the proper function of the muscles (34). The most severe form of dystrophinopathies, DMD, is caused by out-of-frame mutations that disturb the reading frame and are associated with a lower level of protein, $<5 \%$ than the normal level of protein in skeletal muscle (1). In the allelic form, BMD, the mutations that occurred in the DMD gene do not disturb the reading frame that determines the production of a shorter but functional protein in muscle $(35,36)$. 
Mdx mouse. Mouse models are not the best models for DMD disease, but they are widely used for the study of DMD therapies for a few reasons: They are easy to take care of, they have a small body size, the cost associated with their maintenance is acceptable and breeding them is an advantage (21 days of pregnancy for mouse females). In addition, the mouse genome is strongly defined and is largely comparable to the human genome (33).

A general problem for different mouse models developed for DMD is represented by the limitation of clinical manifestation/symptomatology of the human muscular dystrophy (37). This aspect may be present due to the dysregulation of the offsetting mechanism or to a species-specific function of the muscle. Although 20 species of different dog breeds were identified with dystrophy deficiency, most of the studies were only case reports (38).

The dystrophin gene is the first gene discovered to be involved in a type of muscular dystrophy, and due to the DMD phenotype is the most severe form of the disease, and it has been the most studied disease over the last 3 decades $(2,39)$.

The first dystrophin-deficient mouse naturally occurring was discovered by chance in 1984 by Bulfield et al (40) in an experiment for the determination of glycolytic enzyme activity mutants. This mouse model C57BL/10ScSn-Dmdmdx/J, carries a nonsense point mutation in exon 23 in the $D M D$ gene $(3185 \mathrm{C}>\mathrm{T})$ which a premature stop codon leads to the absence of full-length dystrophin and is known as the ' $m d x$-mouse'.

The mouse exhibits muscular dystrophy but does not manifest clear clinical symptoms of muscular dystrophy $(41,42)$. For example, muscle degeneration in $m d x$ mice is different from DMD patients. The fibrosis is less severe than in DMD patients, who also exhibit abnormal cardiac function and a different rate of disease progression (43). Nevertheless, the mice present similar features to human diseases such as muscle weakness, an increased level of muscle creatinine kinase (44), and a shorter lifespan than controls (45).

Thus, this $m d x$ mouse model has been used over the years in preclinical research for efficacy testing of the potential of a new drug $(14,46)$, for dystrophin restoration by stem cell transplantation (15), precursor cells (47), and exon skipping strategy using antisense oligonucleotide for stop-codon read-through (48).

Additional newer strains of $m d x$ mice have been described such as $m d x^{2 \mathrm{cv}}, m d x^{4 \mathrm{cv}}$ and $m d x^{5 \mathrm{cv}}$ over time that facilitate analysis of the role of the dystrophin isoforms (49). In addition, to exacerbate the phenotype, $\mathrm{mdx}$ variants and double-knockout animals have been developed.

Consequently, scientists succeeded in obtaining a better model (DBA/J2-mdx), which exhibited a closer phenotype to the dystrophic diseases with improved fibrosis and less regeneration, however the myocardial pathology and hemodynamic defects suggest that this mouse represents an inadequate model for DMD cardiomyopathy $(16,43)$.

Originating from the $m d x$ model, for a better understanding of the pathophysiology of the disease, a series of $m d x$ variants and double knockout mice models that combine dystrophin mutation of the mdx mouse with mutations in an additional gene in order to exacerbate the phenotype have been generated (50). For dystrophinopathies, a double knockout mouse model for dystrophin and utrophin (a dystrophin homolog protein whose presence compensates for dystrophin deficiency and prevents pathology), $m d x / U t r n^{-/}$displays a more severe phenotype, develops signs of cardiomyopathy and is more suitable to use in experiments $(51,52)$. In addition, $m d x^{4 \mathrm{cv}} / m T R^{\mathrm{G} 2}$ that includes 'humanized' telomere lengths, and exhibits dilated cardiomyopathy appears to be the model that recapitulates both the skeletal muscle as well as the cardiac DMD phenotypes (53). This model was used to demonstrate that long telomeres protect the mice from lethal cardiac disease (54) and contributes to the high regenerative capacity of mouse muscle (55).

Canine model. Several dog breeds such as the Irish Terrier (56), Rottweiler (47,57), Cavalier King Charles Spaniel (58), Golden Retriever $(59,60)$, have been reported and clinically characterized with naturally occurring dystrophin deficiency. Of these, the Golden Retriever muscular dystrophy (GRMD) dog remains the most widely used animal model and the best characterized for the study of DMD pathogenesis and treatment development. The canine model Golden Retriever for Duchenne dystrophy (GRMD) presents an expression of muscular dystrophy phenotype closer to human DMD with lethal respiratory distress and cardiomyopathy. In the GRMD dog, an $A$ to $G$ transition near the end of intron 6 disturbs the acceptor site, causing exon 7 skipping, resulting in a stop codon in exon 8 and arising in a frameshift mutation which leads to lack of dystrophin $(61,62)$. This canine model has the advantage of sharing numerous similar features with the human DMD phenotype regarding severity and selective muscle injury $(17,18)$ and also the body mass of an adult dog is comparable to DMD patients (19). Recently, a dystrophin-deficient male Border collie dog was identified with several naturally-occurring mutations in the DMD gene (deletion of thymine in exon 20 and non-synonymous substitutions in exons 15 and 34) at the age of 5 months (23). The dog presented a relatively mild phenotype and progressive disease similar to DMD patients and could have value as a preclinical model for testing the safety and efficacy of a new drug, and for analysis of the therapeutic potential of various approaches strategies such as exon skipping (63).

However, although, the studies conducted on GRMD dogs are more informative, GRMD dogs are less used in clinical studies of different therapies in contrast with different types of the $m d x$ mouse models due to the adversity of carrying the affected dogs, of the high associated cost with care and management (64).

Although a different number of animals may develop dystrophin-deficient syndrome, the murine and canine models for DMD are the most used animals in pre-clinical testing and although the mouse is a strong model, affected dogs exhibit a better response in clinical and immunological progression compared to humans (65).

Pig models. Because the pig shares several similarities with humans such as the genome (20), size, anatomy, physiology, and pathology (66) it is an attractive animal model to study highly prevalent genetic human diseases. To date, several genetic engineering porcine models of human disease have been created by somatic cell nuclear transfer (67), technologies for genome editing (TALENs) and the CRISPR/Cas9 system (24). 
The pig has also been demonstrated to be an option for muscular dystrophy studies. In 2013, Klymiuk et al reported the generation of a transgenic DMD male pig model with exon 52 deleted by gene targeting and generated offspring by nuclear transfer. The obtained pig model (DMD $\Delta 52)$ displayed some common features with human dystrophy such as loss of dystrophin in skeletal muscle, high level of serum creatine kinase and muscle fibrosis (67). However, the model also has some drawbacks such as a high level of utrophin when compared with age-matched WT pigs and a short lifespan of the animals (67). Recently, Moretti et al were successful in restoring the expression of a shortened dystrophin in a DMD $\Delta 52$ pig model (25). The loss of exon 52 in the DMD gene is a frequent mutation found in DMD patients (68). This porcine model could be useful for the development of different therapeutic strategies for DMD patients.

Another porcine model was generated using the CRISPR/Cas9 system targeting the DMD gene at exon 27. The DMD-modified pigs displayed a low level of dystrophin protein, reduction of movement ability, and cardiac involvement similar to DMD patients. Unfortunately, the founder pigs succumbed, and the cause of death was not specified (69).

A missense mutation $(\mathrm{C}>\mathrm{T}, \mathrm{R} 1958 \mathrm{~W})$ in exon 41 of the DMD which changes arginine to tryptophan was identified in pigs and characterized as spontaneous mutation $(70,71)$ In addition, a case of human Becker muscular dystrophy (BMD)-like myopathy with dystrophin abnormality was identified and described in a pig (72).

As an advantage, the pig and the dog compared with mouse models, have a closer immune system to humans and their body size also is comparable with pre-teenage humans. The pregnancy period for female dogs (58-68 days) and mother sows (124 days) represents a disadvantage for these species in gene therapy studies in DMD (25).

Unfortunately, although the pig represents a favorable option for pre-clinical therapy studies, they succumb early, most of them in the first week of life and none of them live long enough for natural breeding. Another important aspect is represented by human perception of different species involved in animal experiments (12). It is well known that humans have a high affinity for dogs, and non-governmental organizations are fighting for animal welfare and rights all around the world.

\section{Therapeutic strategies in DMD animal models}

In the absence of curative treatment for this progressive and devastating disease, several therapeutic strategies in animal models have been developed over recent years in order to slow down the progression of DMD, to potentially improve the quality of life, or prolong the survival of patients. The progress made thus far in understanding disease progression and pathogenesis has been achieved both with animal models with naturally occurring mutations and developed by genetic engineering (73).

In recent years, several potential strategies have been developed and investigated as promising DMD therapeutic approaches that aimed to ameliorate the DMD phenotype, either by restoring dystrophin expression or by compensating for dystrophin deficiency (74).

\section{Therapies aimed to restore dystrophin expression}

Of specific emerging therapeutic strategies aimed to restore dystrophin expression the most advanced and promising results are the read-through, exon skipping or using the CRISPR/Cas9 system.

Read-through therapies. The occurrence of a premature termination codon within the coding regions of mRNA due to nonsense mutations determines the incorrect termination of translation and production of non-functional, truncated proteins (75). Only DMD patients carrying nonsense mutations ( $\sim 10 \%$ of all), may benefit from read-through therapy (76).

Read-through therapy relies on the use of small molecules (aminoglycosides) that enable recognition and ignore the stop codon thus allowing the production of a functional version of the protein (65). Gentamicin has been the most used aminoglycoside antibiotic that facilitates the read-through of premature stop codons in DMD (75).

The therapeutic properties of gentamicin were demonstrated for the first time in experiments on $m d x$ mice with a mutation in exon 23 in the DMD gene (77). It has been revealed that gentamycin administration can restore dystrophin expression up to $\sim 10-20 \%$ of normal protein level in the muscle $(77,78)$. A large variety of aminoglycosides have been tested for their read-through properties in various animal models (26). Due to the side effects identified in humans, most common nephrotoxicity and ototoxicity, its use in treatment was dismissed (79).

Subsequent efforts were directed towards the discovery and development of novel synthetic aminoglycosides with enhanced read-through activity and reduced toxicity. Translarna (ataluren) is a novel drug used for correction of nonsense mutations by read-through, that was approved for human use after numerous experiments on the $m d x$ mouse model for DMD (80). Contrasting results obtained by different research groups on animal models has led to inefficient treatment of nonsense mutations but with an impact on disease progression (81).

Exon skipping. In the DMD phenotype, the mutations that occur in the $D M D$ gene disrupt the open reading frame and lead to the absence of a functional dystrophin protein in muscle fibers, while in the less severe allelic BMD phenotype the open reading frame is maintained and a shorter but functional dystrophin protein is produced (35). The lack of treatment for the severe phenotype has led to the development of a strategy to transform the DMD phenotype into BMD by modulating splicing of the dystrophin mRNA and skip exons containing mutations that disrupt the open reading frame $(68,82)$. The reading frame correction can be mediated by antisense oligonucleotides (ASOs) or using CRISPR-Cas9 gene editing.

The potential of antisense oligonucleotide-mediated exon skipping therapy using several types of antisense oligonucleotides targeting exon 51 was evaluated in the $m d x$ mouse model (83), and a canine model (84). The results were promising and 2- $O$-methyl-phosphorothioate (2OMePS) $(82,85)$ and morpholino-phosphorodiamidate oligomer (PMO) (27) have been translated into clinical trials. The studies have been 
extended to other exons and are currently being investigated in exons 42, 52, 53, and 55 (86).

Although this therapy has been demonstrated to be a powerful tool for restoring the open reading frame numerous challenges remain regarding the stability, delivery, efficacy, and toxicity of AONs (87).

Clustered regularly interspaced short palindromic repeats/CRISPR-associated protein 9 (CRISPR/Cas9) technology (88) is the most promising genetic-engineering tool for editing genomes. The technology has been used to introduce a desired small or large DNA modification in different cell types and organisms (89). The approach has been applied successfully in restoring an open reading frame and increasing the expression of a shortened dystrophin in a mouse model (del52hDMD/mdx) (90) and a pig model (DMD $\Delta 52)$ (25).

With the use of this approach, the efficiency and stability of the genetic modification were significantly improved (91). However, numerous questions remain concerning the safety and effectiveness of the technology when used in humans.

\section{Therapies aimed to compensate the lack of dystrophin}

The advantage of compensatory approaches, in contrast to restorative approaches, is that they are intended for all patients with DMD regardless of the type of mutation.

Among the therapeutic strategies which are aimed to compensate for the lack of dystrophin that are thought to have an important value in treating these diseases, are utrophin upregulation, myostatin inhibition, reduction of inflammation and fibrosis, and neuronal nNOS pathway enhancement (92-96).

Of all these potential therapeutic strategies, upregulation of utrophin is a highly promising approach and utrophin is a promising candidate to compensate for the lack of dystrophin (97). Utrophin or dystrophin-related protein (DRP) is an autosomal gene that exhibits $80 \%$ homology with dystrophin, has similar molecular weight and structure (98), and can perform similar functions (99). Due to its homology and other criteria, the possibility of compensating the loss of dystrophin with upregulation of utrophin has been investigated in numerous experiments using $m d x$ utrn $^{-/}$mice (100) as well as in the dystrophin/utrophin $\left(m d x / u t r n^{-/}\right)$double-knock out mouse model $(101,102)$. The results of the experiments have revealed that utrophin ameliorates all mechanical performances of the muscle (95), increased utrophin levels are not toxic to tissues (103) and appear promising to endorse utrophin modulation as a therapeutic strategy for DMD patients.

\section{Animal models for other types of muscular dystrophies}

LGMD are a group of heterogeneous rare progressive genetic disorders characterized by muscle wasting and weakness of the voluntary muscles of the limb girdle area. There are $>30$ types of LGMD with specific features such as the age of onset, the severity of disease, phenotype, and pathology. They are caused by mutations that occur in numerous different genes (104).

Based on its inheritance pattern and genetic cause, LGMDs are classified into two subtypes: Type 1 with an autosomal dominant inheritance pattern and type 2 with autosomal recessive transmission (105).
With regard to LGMD type 2, the most common forms with the highest incidence are sarcoglycanopathies (LGMD 2D, 2E, $2 \mathrm{C}$, and $2 \mathrm{~F}$ ), a group of autosomal recessive muscle-wasting disorders caused by mutations in the genes that encode for cell membrane glycoproteins, $\alpha-, \beta$-, $\gamma$ - or $\delta$-sarcoglycan, as well as calpainopathy (LGMD2A) caused by mutations in the CAPN3 gene that encodes for calpain 3 (106).

Animal models of calpain 3 deficiency. There is no causative treatment for this disease to date (107). In order to understand the calpainopathy disease mechanism and testing potential therapeutics, several animal CAPN3-knockout models have been developed.

One mouse model of calpain 3 knockout was generated by Richard et al in 2000 (108), with disrupted proteolytic site of calpain 3 by substituting exons 2 and 3 with a neoR cassette using homologous recombination. Phenotypically, the muscles revealed regions of focal necrosis and apoptosis of nuclei with a complete absence of calpain 3 protein (108). Another mouse was generated by using a gene trap retroviral vector that introduced premature stop signals that completely abolished mRNA and protein expression. The phenotype exhibited muscle necrosis in combination with fibre atrophy and closely resembled LGMD2A (109,110). These animal models used in the aforementioned studies revealed the importance of calpain 3 in $\mathrm{Ca} 2^{+}$release in muscle fibers and its participation in sarcomere remodelling by promoting ubiquitination of its ligands (111).

A previous study revealed that the accumulation of aged and damaged proteins in old $\mathrm{C} 3 \mathrm{KO}$ mice leads to cellular toxicity and a cell stress response in the muscle of mice (111). Recently, a severe double-knockout mouse model (dKO) deficient in calpain 3 and dysferlin was developed by Lostal et al (112) to investigate the mechanism of the cardiac toxicity that previously was observed in mice.

Animal models of sarcoglycanopathies deficiency. There are a great number of animal models of sarcoglycanopathies, however the hamster was the first animal model and is the most well described (113).

Mice are also a classical model used to study the pathology of the $\alpha-, \beta-, \gamma$ - and $\delta$-sarcoglycanopathies, respectively. These models have revealed progressive muscle pathology and functional impairments of variable severity (109). Notably, all sarcoglycan-null models except the Sgca-null mice develop a cardiac phenotype (33). A new variation of the Sgcg-null mouse has been generated (the $521 \Delta \mathrm{T}$ mouse) which has a single nucleotide deletion in exon 6 , corresponding to the most common mutation found in humans (114).

\section{Ethical concerns and animal models}

Using experimental animals for scientific research in human medicine and the implementation of new techniques and procedures for developing new animal models for research represents a necessity both for human medicine and for scientific fields. Nowadays, researchers are developing humanized animal models for numerous genetic diseases (115).

Romanian legislation on the use of animals in biological research. The legislation regarding the use of animals for 
experimental scientific research has been developed worldwide and is the result of public and non-governmental organisations, concerned with the welfare of laboratory animals. Regarding the current legislation on the protection of animals used for scientific research, in Romania, the EU Directive no. 63/2010/ was transferred in the current Law no. 43/11 April/2014. For projects conducted on laboratory animals and for projects authorization procedures, since 2015 in Romania the Order no. 97/2015 of the President of National Sanitary Veterinary and Food Safety Agency (NSVFSA) is in effect.

In Romania, for project authorization a two-step procedure must be followed: i) The applicant requires the approval of the institutional Ethics Committee; and ii) the applicant requires the authorization of the regional Sanitary Veterinary authority (116). Correct implementation and use of laws regarding the projects conducted on laboratory animals are necessary for quality of scientific research but also for animal welfare. It is well known that the welfare of laboratory animals during the experiments influences the effects or experimental results and may lead to erroneous or even inaccurate results in scientific fields (117). On the other hand, most countries already have groups of non-governmental organisations that are promoting laboratory animal welfare, trying to stop the use of animals for scientific research, even in the testing of treatments for rare diseases.

\section{Conclusion}

With regard to muscular dystrophy as a progressive and fatal disease, where Duchenne and Becker muscular dystrophy (DMD and BMD) are the most common, different methods are used for targeted therapies with the goal of prevention of the disease or to stop some other related diseases such as cardiomyopathy. In consequence, a wide variety of disease animal models naturally occurring, or laboratory-generated have been used for testing targeted therapies and their efficacy $(9,30,31)$.

The contrast between animal models in their body size, phenotype, disease expression and response to therapeutic treatments in comparison with humans highlight the need and the necessity of developing new models for study $(31,117)$. Identification and characterization of laboratory animal models for dystrophinopathies would improve the understanding of the diseases, the molecular mechanism, and the possibility of testing future therapies. Although, nowadays, the activity and the manifestations of non-governmental organisations regarding the animal welfare of laboratory animals are present worldwide, developing animal models for therapeutic approaches and for studying important diseases such as muscular dystrophies are mandatory.

For consideration of muscular dystrophy animal models, a few aspects are necessary: The cost of maintenance of animals in laboratory must be low or acceptable, animals should be cared for compassionately and their well-being must be of utmost importance considering the fact that animals cannot move normally due to their dystrophinopathy and the animal survival rate with the associated pathology such as cardiomyopathies should be long enough. The gestation period of animals should be short, and the survival rate of the progenitors must be high enough and most important, animals should best express the human phenotype.
The advances of the last years in gene therapy and the improvement of animal models and methods of analysis have led us closer to finding a treatment for muscular dystrophies.

\section{Acknowledgements}

Not applicable.

\section{Funding}

The present study was supported by grants from the Ministry of Research and Innovation in Romania, under Program 1-The Improvement of the National System of Research and Development, Subprogram 1.2-Institutional ExcellenceProjects of Excellence Funding in RDI, Contract No. 7PFE/16.10.2018; National Program 31N/2016/PN 16.22.02.05 and $1 \mathrm{~N} / 2019 / \mathrm{PN} 19.29 .01 .03$

\section{Availability of data and materials}

Not applicable.

\section{Authors' contributions}

GG proposed the article subject and conceived the study. GG and $A G$, equally contributed to the writing and revision of the manuscript, as well as read and approved the final version.

\section{Ethics approval and consent to participate}

Not applicable.

\section{Patient consent for publication}

Not applicable.

\section{Competing interests}

The authors declare that they have no competing interests.

\section{References}

1. Dalkilic I and Kunkel LM: Muscular dystrophies: Genes to pathogenesis. Curr Opin Genet Dev 13: 231-238, 2003.

2. Hoffman EP, Brown RH Jr and Kunkel LM: Dystrophin: The protein product of the Duchenne muscular dystrophy locus. Cell 51: 919-928, 1987.

3. Ervasti JM and Campbell KP: A role for the dystrophinglycoprotein complex as a transmembrane linker between laminin and actin. J Cell Biol 122: 809-823, 1993.

4. Ibraghimov-Beskrovnaya O, Ervasti JM, Leveille CJ, Slaughter CA, Sernett SW and Campbell KP: Primary structure of dystrophin-associated glycoproteins linking dystrophin to the extracellular matrix. Nature 355: 696-702, 1992.

5. Lapidos KA, Kakkar R and McNally EM: The Dystrophin glycoprotein complex: Signaling strength and integrity for the sarcolemma. Circ Res 94: 1023-1031, 2004.

6. Constantin B: Dystrophin complex functions as a scaffold for signalling protein. Biochim Biophys Acta 1838: 635-642, 2014.

7. Gaina G: Clinical and molecular diagnosis in muscular dystrophies. Ed Intech, 2019.

8. Bushby K, Norwood F and Straub V: The limb-girdle muscular dystrophies-Diagnostic strategies. Biochim Biophys Acta 1772: 238-242, 2007.

9. McNally EM and Pytel P: Muscle diseases: The muscular dystrophies. Annu Rev Pathol 2: 87-109, 2007. 
10. Matthews RA: Medical progress depends on animal models-doesn't it? J R Soc Med 101: 95-98, 2008.

11. Barré-Sinoussi F and Montagutelli S: Animal models are essential to biological research: Issues and perspectives. Future Sci OA 1: FSO63, 2015.

12. Wells D: Tracking progress: An update on animal models for Duchenne muscular dystrophy. Dis Model Mech 11: dmm035774, 2018.

13. Van Putten M, Lloyd EM, de Greef JC, Raz V, Willmann R and Grounds MD: Mouse models for muscular dystrophies: An overview. Dis Model Mech 13: dmm043562, 2020.

14. Spurney C, Gordish-Dressman H, Guerron AD, Sali A, Pandey GS, Rawat R, Van Der Meulen JH, Cha HJ, Pistilli EE, Partridge TA, et al: Preclinical drug trials in the mdx mouse: Assessment of reliable and sensitive outcome measures. Muscle Nerve 39: 591-602, 2009

15. Gussoni E, Soneoka Y, Strickland CD, Buzney EA, Khan MK, Flint AF, Kunkel LM and Mulligan RC: Dystrophin expression in the mdx mouse restored by stem cell transplantation. Nature 401: 390-394, 1999

16. Hakim CH, Wasala NB, Pan X, Kodippili K, Yue Y, Zhang K, Yao G, Haffner B, Duan SX, Ramos J, et al: A five-repeat micro-dystrophin gene ameliorated dystrophic phenotype in the severe DBA/2J-mdx model of Duchenne muscular dystrophy. Mol Ther Methods Clin Dev 6: 216-230, 2017.

17. Kornegay JN: The golden retriever model of Duchenne muscular dystrophy. Skelet Muscle 7: 9, 2017.

18. Kornegay JN, Bogan JR, Bogan DJ, Childers MK, Li J, Nghiem P, Detwiler DA, Larsen CA, Grange RW, Bhavaraju-Sanka RK, et al: Canine models of Duchenne muscular dystrophy and their use in therapeutic strategies. Mamm Genome 23: 85-108, 2012.

19. Howell JM, Fletcher S, Kakulas BA, O'Hara M, Lochmuller H and Karpati G: Use of the dog model for Duchenne muscular dystrophy in gene therapy trials. Neuromuscul Disord 7: 325-328, 1997.

20. Wernersson R, Schierup MH, Jørgensen FG, Gorodkin J, Panitz F, Stærfeldt HH, Christensen OF, Mailund T, Hornshøj H, Klein A, et al: Pigs in sequence space: A $0.66 \mathrm{X}$ coverage pig genome survey based on shotgun sequencing. BMC Genomics 6 : 70, 2005 .

21. Guiraud S, Squire SE, Edwards B, Chen H, Burns DT, Shah N, Babbs A, Davies SG, Wynne GM, Russell AJ, et al: Second generation compound for the modulation of utrophin in the therapy of DMD. Hum Mol Genet 24: 4212-4224, 2015.

22. Witting N, Kruuse C, Nyhuus B, Prahm KP, Citirak G, Lundgaard SJ, von Huth S, Vejlstrup N, Lindberg U, Krag TO and Vissing J: Effect of sildenafil on skeletal and cardiac muscle in Becker muscular dystrophy. Ann Neurol 76: 550-557, 2014.

23. Mata López S, Hammond JJ, Rigsby MB, Balog-Alvarez CJ, Kornegay JN and Nghiem PP: A novel canine model for Duchenne muscular dystrophy (DMD): Single nucleotide deletion in DMD gene exon 20. Skelet Muscle 8: 16, 2018.

24. Whitworth KM, Lee K, Benne JA, Beaton BP, Spate LD Murphy SL, Samuel MS, Mao J, O'Gorman C, Walters EM, et al: Use of the CRISPR/Cas9 system to produce genetically engineered pigs from in vitro-derived oocytes and embryos. Biol Reprod 91: 78, 2014.

25. Moretti A, Fonteyne L, Giesert F, Hoppmann P, Meier AB Bozoglu T, Baehr A, Schneider CM, Sinnecker D, Klett K, et al: Somatic gene editing ameliorates skeletal and cardiac muscle failure in pig and human models of Duchenne muscula dystrophy. Nat Med 26: 207-214, 2020.

26. Du M, Keeling KM, Fan L, Liu X, Kovaçs T, Sorscher E and Bedwell DM: Clinical doses of amikacin provide more effective suppression of the human CFTR-G542X stop mutation than gentamicin in a transgenic CF mouse model. J Mol Med (Berl) 84: 573-582, 2006

27. Kayali R, Ku JM, Khitrov G, Jung ME, Prikhodko O and Bertoni C: Read-through compound 13 restores dystrophin expression and improves muscle function in the mdx mouse model for Duchenne muscular dystrophy. Hum Mol Genet 21: 4007-4020, 2012.

28. Valentine BA, Cooper BJ, de Lahunta A, O'Quinn R and Blue JT: Canine X-linked muscular dystrophy. An animal model of Duchenne muscular dystrophy: Clinical studies. J Neurol Sci 88 69-81, 1988

29. Beastrom N, Lu H, Macke A, Canan BD, Johnson EK Penton CM, Kaspar BK, Rodino-Klapac LR, Zhou L, Janssen PM and Montanaro F: $\mathrm{mdx}\left({ }^{5} \mathrm{cv}\right)$ mice manifest more severe muscle dysfunction and diaphragm force deficits than do mdx Mice. Am J Pathol 179: 2464-2474, 2011
30. Wolfe JH: Gene therapy in large animal models of human genetic diseases. Introduction. ILAR J 50: 107-111, 2009.

31. Allamand V and Campbell K: Animal models for muscular dystrophy: Valuable tools for the development of therapies. Hum Mol Genet 9: 2459-2467, 2000

32. Acosta CA, Izal I, Ripalda P, Douglas-Price AL and Forriol F: Gene expression and proliferation analysis in young, aged, and osteoarthritic sheep chondrocytes effect of growth factor treatment. J Orthop Res 24: 2087-2094, 2006.

33. Mouse Genome Sequencing Consortium; Waterston RH Lindblad-Toh K, Birney E, Rogers J, Abril JF, Agarwal P, Agarwala R, Ainscough R, Alexandersson M, et al: Initial sequencing and comparative analysis of the mouse genome. Nature 420: 520-562, 2002.

34. Emery AEH and Muntoni F (eds.): Duchenne Muscular Dystrophy. Oxford University Press, New York, NY, 2003.

35. Koenig M, Beggs AH, Moyer M, Scherpf S, Heindrich K, Bettecken T, Meng G, Müller CR, Lindlöf M, Kaariainen H, et al: The molecular basis for Duchenne versus Becker muscular dystrophy: Correlation of severity with type of deletion. Am J Hum Genet 45: 498-506, 1989.

36. Di Blasi L, Morandi L, Barresi R, Blasevich F, Cornelio F and Mora M: Dystrophin-associated protein abnormalities in dystrophin-deficient muscle fibers from symptomatic and asymptomatic Duchenne/Becker muscular dystrophy carriers. Acta Neuropathol (Berl) 92: 369-377, 1996.

37. Rodgers BD, Bishaw Y, Kagel D, Ramos JN and Maricelli JW: Micro-dystrophin gene therapy partially enhances exercise capacity in older adult mdx mice. Mol Ther Methods Clin Dev 17: 122-132, 2019.

38. McGreevy JW, Hakim CH, McIntosh MA and Duan D: Animal models of Duchenne muscular dystrophy: From basic mechanisms to gene therapy. Dis Model Mech 8: 195-213, 2015.

39. Koenig M, Monaco AP and Kunkel LM: The complete sequence of dystrophin predicts a rod-shaped cytoskeletal protein. Cell 53: 219-226, 1988

40. Bulfield G, Siller WG, Wight PA and Moore KJ: X chromosome-linked muscular dystrophy ( $\mathrm{mdx}$ ) in the mouse. Proc Natl Acad Sci USA 81: 1189-1192, 1984.

41. Sicinski P, Geng Y, Ryder-Cook AS, Barnard EA, Darlison MG and Barnard PJ: The molecular basis of muscular dystrophy in the mdx mouse: A point mutation. Science 244: 1578-1580, 1989.

42. Morgan SJ, Elangbam CS, Berens S, Janovitz E, Vitsky A, Zabka $\mathrm{T}$ and Conour L: Use of animal models of human disease for nonclinical safety assessment of novel pharmaceuticals. Toxicol Pathol 41: 508-518, 2013

43. Fukada S, Morikawa D, Yamamoto Y, Yoshida T, Sumie N, Yamaguchi M, Ito T, Miyagoe-Suzuki Y, Takeda S, Tsujikawa K and Yamamoto H: Genetic background affects properties of satellite cells and mdx phenotypes. Am J Pathol 176: 2414-2424, 2010

44. Carnwath JW and Shotton DM: Muscular dystrophy in the mdx mouse: Histopathology of the soleus and extensor digitorum longus muscles. J Neurol Sci Aug 80: 39-54, 1987.

45. Manning $\mathbf{J}$ and $\mathrm{O}^{\prime}$ Malley D: What has the mdx mouse model of Duchenne muscular dystrophy contributed to our understanding of this disease? J Muscle Res Cell Motil 36: 155-167, 2015.

46. De Luca A, Nico B, Liantonio A, Didonna MP, Fraysse B, Pierno S, Burdi R, Mangieri D, Rolland JF, Camerino C, et al: A multidisciplinary evaluation of the effectiveness of cyclosporine A in dystrophic mdx mice. Am J Pathol 166: 477-489, 2005.

47. Partridge TA, Morgan JE, Coulton GR, Hoffman EP and Kunkel LM: Conversion of mdx myofibres from dystrophin-negative to -positive by injection of normal myoblasts. Nature 337: $176-179,1989$.

48. Roy P, Rau F, Ochala J, Messéant J, Fraysse B, Lainé J, Agbulut O, Butler-Browne G, Furling D and Ferry A: Dystrophin restoration therapy improves both the reduced excitability and the force drop induced by lengthening contractions in dystrophic mdx skeletal muscle. Skelet Muscle 6: 23, 2016.

49. Im WB, Phelps FS, Copen RH, Adams EG, Slightom JL and Chamberlain JS: Differential expression of Dystrophin isoforms in strains of mdx mice with different mutations. Hum Mol Genet 5: 1149-1153, 1996.

50. Bürger R, Willensdorfer M and Nowak MA: Why are phenotypic mutation rates much higher than genotypic mutation rates? Genetics 172: 197-206, 2006.

51. Grady RM, Teng H, Nichol MC, Cunningham JC, Wilkinson RS and Sanes JR: Skeletal and cardiac myopathies in mice lacking utrophin and dystrophin: A model for Duchenne muscular dystrophy. Cell 90: 729-738, 1997. 
52. Davies KE and Chamberlain JS: Surrogate gene therapy for muscular dystrophy. Nat Med 25: 1473-1474, 2019.

53. Yucel N, Chang AC, Day JW, Rosenthal N and Blau HM: Humanizing the mdx mouse model of DMD: The long and the short of it. NPJ Regen Med 3: 4, 2018.

54. Chang AC, Ong SG, LaGory EL, Kraft PE, Giaccia AJ, Wu JC and Blau HM: Telomere shortening, and metabolic compromise underlie dystrophic cardiomyopathy. Proc Natl Acad Sci USA 113: 13120-13125, 2016

55. Mourkioti F, Kustan J, Kraft P, Day JW, Zhao MM Kost-Alimova M, Protopopov A, DePinho RA, Bernstein D, Meeker AK and Blau HM: Role of telomere dysfunction in cardiac failure in Duchenne muscular dystrophy. Nat Cell Biol 15: 895-904, 2013

56. Wentink GH, van der Linde-Sipman JS, Meijer AEFH, Kamphuisen HAC, van Vorstenbosch CJAHV, Hartman W and Hendriks HJ: Myopathy with a possible recessive X-linked inheritance in a litter of Irish Terriers. Vet Pathol 9: 328-349, 1972.

57. Cooper BJ, Gallagher EA, Smith CA, Valentine BA and Winand NJ: Mosaic expression of dystrophin in carriers of canine X-linked muscular dystrophy. Lab Invest 62: 171-178, 1990.

58. Walmsley GL, Arechavala-Gomeza V, Fernandez-Fuente M, Burke MM, Nagel N, Holder A, Stanley R, Chandler K, Marks SL, Muntoni F, et al: A duchenne muscular dystrophy gene hot spot mutation in dystrophin-deficient cavalier king charles spaniels is amenable to exon 51 skipping. PLoS One 5: e8647, 2010.

59. Meier H: Myopathies in the dog. Cornell Vet 48: 313-330, 1958.

60. Cooper BJ, Winand NJ, Stedman H, Valentine BA, Hoffman EP, Kunkel LM, Scott MO, Fischbeck KH, Kornegay JN, Avery RJ, et al: The homologue of the Duchenne locus is defective in X-linked muscular dystrophy of dogs. Nature 334 154-156, 1988

61. Sharp NJ, Kornegay JN, Van Camp SD, Herbstreith MH, Secore SL, Kettle S, Hung WY, Constantinou CD, Dykstra MJ, Roses $\mathrm{AD}$, et al: An error in dystrophin mRNA processing in golden retriever muscular dystrophy, an animal homologue of Duchenne muscular dystrophy. Genomics 13: 115-121, 1992.

62. Schatzberg SJ, Olby NJ, Breen M, Anderson LV, Langford CF, Dickens HF, Wilton SD, Zeiss CJ, Binns MM, Kornegay JN, et al: Molecular analysis of a spontaneous dystrophin 'knockout' dog. Neuromuscul Disord 9: 289-295, 1999.

63. Vulin A, Barthélémy I, Goyenvalle A, Thibaud JL, Beley C, Griffith G, Benchaouir R, le Hir M, Unterfinger Y, Lorain S, et al: Muscle function recovery in golden retriever muscular dystrophy after AAV1-U7 exon skipping. Mol Ther 20: 2120-2133, 2012.

64. Wasala N, Chen SJ and Duan D: Duchenne muscular dystrophy animal models for high-throughput drug discovery and precision medicine. Expert Opin Drug Discov 15: 443-456, 2020.

65. Nghiem PP and Kornegay JN: Gene therapies in canine models for Duchenne muscular dystrophy. Hum Genet 138: 483-489, 2019.

66. Lunney JK: Advances in swine biomedical model genomics. Int J Biol Sci 3: 179-184, 2007.

67. Klymiuk N, Blutke A, Graf A,Krause S, Burkhardt K, Wuensch A Krebs S, Kessler B, Zakhartchenko V, Kurome M, et al: Dystrophin-deficient pigs provide new insights into the hierarchy of physiological derangements of dystrophic muscle. Hum Mol Genet 22: 4368-4382, 2013

68. Muntoni F, Torelli S and Ferlini A: Dystrophin and mutations: One gene, several proteins, multiple phenotypes. Lancet Neurol 2: 731-740, 2003

69. Yu HH, Zhao H, Qing YB, Pan WR, Jia BY, Zhao HY, Huang XX and Wei HJ: Porcine zygote injection with Cas9/sgRNA results in DMD-modified pig with muscle dystrophy. Int J Mol Sci 17: 1668,2016

70. Nonneman DN, Brown-Brandl T, Jones SA, Wiedmann RT and Rohrer GA: A defect in dystrophin causes a novel porcine stress syndrome. BMC Genomics 13: 233, 2012

71. Hollinger K, Yang CX, Montz RE, Nonneman D, Ross JW and Selsby JT: Dystrophin insufficiency causes selective muscle histopathology and loss of dystrophin-glycoprotein complex assembly in pig skeletal muscle. FASEB J 28: 1600-1609, 2014.

72. Horiuchi N, Aihara N, Mizutani H, Kousaka S, Nagafuchi T, Ochiai M, Kobayashi Y, Furuoka H, Asai T and Oishi K: Becker muscular dystrophy-like myopathy regarded as so-called 'fatty muscular dystrophy' in a Pig: A case report and its diagnostic method. J Vet Med Sci 76: 243-248, 2014
73. Guiraud S, Aartsma-Rus A, Vieira NM, Davies KE, van Ommen GJB and Kunkel LM: The pathogenesis and therapy of muscular Dystrophies. Annu Rev Genomics Hum Genet 16: 281-308, 2015

74. Shimizu-Motohashi Y, Komaki H, Motohashi N, Takeda S, Yokota $\mathrm{T}$ and Aoki Y: Restoring Dystrophin expression in duchenne muscular dystrophy: Current status of therapeutic approaches. J Pers Med 9: 1, 2019.

75. Dabrowski M, Bukowy-Bieryllo Z and Zietkiewicz E: Advances in therapeutic use of a drug-stimulated translational readthrough of premature termination codons. Mol Med 24: 25, 2018.

76. Bladen CL, Salgado D, Monges S, Foncuberta ME, Kekou K, Kosma K, Dawkins H, Lamont L, Roy AJ, Chamova T, et al: The TREAT-NMD DMD global database: Analysis of more than 7,000 Duchenne muscular dystrophy mutations. Hum Mutat 36: 395-402, 2015

77. Barton-Davis ER, Cordier L, Shoturma DI, Leland SE and Sweeney HL: Aminoglycoside antibiotics restore dystrophin function to skeletal muscles of $\mathrm{mdx}$ mice. J Clin Invest 104 375-381, 1999.

78. Malik V, Rodino-Klapac LR, Viollet L, Wall C, King W, Al-Dahhak R, Lewis S, Shilling CJ,Kota J, Serrano-Munuera C, etal: Gentamicin-induced readthrough of stop codons in Duchenne muscular dystrophy. Ann Neurol 67: 771-780, 2010

79. Namgoong JH and Bertoni C: Clinical potential of ataluren in the treatment of Duchenne muscular dystrophy. Degener Neurol Neuromuscul Dis 6: 37-48, 2016.

80. Welch EM, Barton ER, Zhuo J, Tomizawa Y, Friesen WJ, Trifillis P, Paushkin S, Patel M, Trotta CR, Hwang S, et al: PTC124 targets genetic disorders caused by nonsense mutations. Nature 447: 87-91, 2007.

81. Dranchak PK, Di Pietro E, Snowden A, Oesch N, Braverman NE, Steinberg SJ and Hacia JG: Nonsense suppressor therapies rescue peroxisome lipid metabolism and assembly in cells from patients with specific PEX gene mutations. J Cell Biochem 112: $1250-1258,2011$

82. Aartsma-Rus A, Janson AA, Kaman WE, Bremmer-Bout M, den Dunnen JT, Baas F, van Ommen GJ and van Deutekom JC: Therapeutic antisense-induced exon skipping in cultured muscle cells from six different DMD patients. Hum Mol Genet 12 907-914, 2003.

83. Aoki Y, Nakamura A, Yokota T, Saito T, Okazawa H, Nagata T and Takeda S: In-frame dystrophin following exon 51-skipping improves muscle pathology and function in the exon 52-deficient mdx mouse. Mol Ther 18: 1995-2005, 2010.

84. McClorey G, Moulton HM, Iversen PL, Fletcher S and Wilton SD: Antisense oligonucleotide-induced exon skipping restores dystrophin expression in vitro in a canine model of DMD. Gene Ther 13: 1373-1381, 2006.

85. van Deutekom JC, Janson AA, Ginjaar IB, Frankhuizen WS, Aartsma-Rus A, Bremmer-Bout M, den Dunnen JT, Koop K, van der Kooi AJ, Goemans NM, et al: Local dystrophin restoration with antisense oligonucleotide PRO051. N Engl J Med 357: 2677-2686, 2007.

86. Nguyen Q and Yokota T: Immortalized muscle cell model to test the exon skipping efficacy for duchenne muscular dystrophy. J Pers Med 7: 13, 2017.

87. Blain AM, Greally E, McClorey G, Manzano R, Betts CA, Godfrey C, O'Donovan L, Coursindel T, Gait MJ, Wood MJ, et al: Peptide-conjugated phosphodiamidate oligomer-mediated exon skipping has benefits for cardiac function in mdx and Cmah-/mdx mouse models of Duchenne muscular dystrophy. PLoS One 13: e0198897, 2018

88. Ishino $\mathrm{Y}$, Shinagawa $\mathrm{H}$, Makino K, Amemura M and Nakata A: Nucleotide sequence of the iap gene, responsible for alkaline phosphatase isozyme conversion in Escherichia coli, and identification of the gene product. J Bacteriol 169: 5429-5433, 1987.

89. Wright A, Nuñez JK and Doudna JA: Biology and Applications of CRISPR Systems: Harnessing Nature's Toolbox for Genome Engineering. Cell 164: 29-44, 2016.

90. Duchêne BL, Cherif K, Iyombe-Engembe JP, Guyon A, Rousseau A, Ouellet DL, Barbeau X, Lague P and Tremblay JP: CRISPR-induced deletion with SaCas9 restores dystrophin expression in dystrophic models in vitro and in vivo. Mol Ther 26: 2604-2616, 2018.

91. Bengtsson NE, Hall JK, Odom GL, Phelps MP, Andrus CR, Hawkins RD, Hauschka SD, Chamberlain JR and Chamberlain JS: Muscle-specific CRISPR/Cas9 dystrophin gene editing ameliorates pathophysiology in a mouse model for Duchenne muscular dystrophy. Nat Commun 8: 14454, 2017. 
92. Gilbert R, Nalbantoglu J, Petrof BJ, Ebihara S, Guibinga GH, Tinsley JM, Kamen A, Massie B, Davies KE and Karpati G: Adenovirus-mediated utrophin gene transfer mitigates the dystrophic phenotype of mdx mouse muscles. Hum Gene Ther 10: 1299-1310, 1999.

93. McPherron AC, Lawler AM and Lee SJ: Regulation of skeletal muscle mass in mice by a new TGF-beta superfamily member. Nature 387: 83-90, 1997.

94. Acharyya S, Villalta SA, Bakkar N, Bupha-Intr T, Janssen PM, Carathers M, Li ZW, Beg AA, Ghosh S, Sahenk Z, et al: Interplay of IKK/NF-kappaB signaling in macrophages and myofibers promotes muscle degeneration in Duchenne muscular dystrophy. J Clin Invest 117: 889-901, 2007.

95. Larsen FJ, Schiffer TA, Borniquel S, Sahlin K, Ekblom B, Lundberg JO and Weitzberg E: Dietary inorganic nitrate improves mitochondrial efficiency in humans. Cell Metab 13: $149-159,2011$

96. Barton ER, Morris L, Kawana M, Bish LT and Toursel T: Systemic administration of L-arginine benefits mdx skeletal muscle function. Muscle Nerve 32: 751-760, 2005.

97. Tinsley JM, Potter AC, Phelps SR, Fisher R, Trickett JI and Davies KE: Amelioration of the dystrophic phenotype of mdx mice using a truncated utrophin transgene. Nature 384: 349-353, 1996.

98. Khurana TS, Hoffman EP and Kunkel LM: Identification of a chromosome 6-encoded dystrophin-related protein. J Biol Chem 265: 16717-16720, 1990.

99. Voisin V and la Porte S: Therapeutic strategies for Duchenne and Becker dystrophies. Int Rev Cytol 240: 1-30, 2004.

100. Deconinck N, Tinsley J, De Backer F, Fisher R, Kahn D, Phelps S, Davies K and Gillis JM: Expression of truncated utrophin leads to major functional improvements in dystrophin-deficient muscles of mice. Nat Med 3: 1216-1221, 1997.

101. Deconinck AE, Rafael JA, Skinner JA, Brown SC, Potter AC, Metzinger L, Watt DJ, Dickson JG, Tinsley JM and Davies KE: Utrophin-dystrophin-deficient mice as a model for Duchenne muscular dystrophy. Cell 90: 717-727, 1997.

102. Grady RM, Teng H, Nichol MC, Cunningham JC, Wilkinson RS and Sanes JR: Skeletal and cardiac myopathies in mice lacking utrophin and dystrophin: A model for Duchenne muscular dystrophy. Cell 90: 729-738, 1997.

103. Fisher R, Tinsley JM, Phelps SR, Squire SE, Townsend ER, Martin JE and Davies KE: Non-toxic ubiquitous over-expression of utrophin in the mdx mouse. Neuromuscul Disord 11: 713-721,2001.

104. Walton JN and Nattrass FJ: On the classification, natural history and treatment of the myopathies. Brain 77: 169-231, 1954.

105. Preisler N, Lukacs Z, Vinge L, Madsen KL, Husu E, Hansen RS, Duno M, Andersen H, Laub M and Vissing J: Late-onset Pompe disease is prevalent in unclassified limb-girdle muscular dystrophies. Mol Genet Metab 110: 287-289, 2013.

106. Bushby KM: Diagnostic criteria for the limb-girdle muscular dystrophies: Report of the ENMC Consortium on Limb-Girdle Dystrophies. Neuromuscul Disord 5: 71-74, 1995.
107. Norwood FL, Harling C, Chinnery PF, Eagle M, Bushby K and Straub V: Prevalence of genetic muscle disease in Northern England: In-depth analysis of a muscle clinic population. Brain 132: 3175-3186, 2009.

108. Richard I, Roudaut C, Marchand S, Baghdiguian S, Herasse M, Stockholm D, Ono Y, Suel L, Bourg N, Sorimachi H, et al: Loss of Calpain 3 Proteolytic activity leads to muscular dystrophy and to apoptosis-associated IkappaBalpha/nuclear Factor kappa Pathway Perturbation in Mice. J Cell Biol 151: 1583-1590, 2000.

109. Bartoli M, Roudaut C, Martin S, Fougerousse F, Suel L, Poupiot J, Gicquel E, Noulet F, Danos O and Richard I: Safety and efficacy of AAV-mediated Calpain 3 gene transfer in a mouse model of limb-girdle muscular dystrophy type $2 \mathrm{~A}$. Mol Ther 13: 250-259, 2006.

110. Ng R, Banks GB, Hall JK, Muir LA, Ramos JN, Wicki J, Odom GL, Konieczny P, Seto J, Chamberlain JR and Chamberlain JS: Animal models of muscular dystrophy. Prog Mol Biol Transl Sci 105: 83-111, 2012.

111. Kramerova I, Kudryashova E, Tidball JG and Spencer MJ: Null mutation of calpain 3 (p94) in mice causes abnormal sarcomere formation in vivo and in vitro. Hum Mol Genet 13: 1373-88, 2004.

112. Lostal W, Roudaut C, Faivre M, Charton K, Suel L, Bourg N, Best H, Smith JE, Gohlke J, Corre G, et al: Titin splicing regulates cardiotoxicity associated with calpain 3 gene therapy for limb-girdle muscular dystrophy type 2A. Sci Transl Med 11: eaat6072, 2019.

113. Blain AM and Straub VW: $\delta$-Sarcoglycan-deficient muscular dystrophy: From discovery to therapeutic approaches. Skelet Muscle 1: 13, 2011.

114. Demonbreun A, Wyatt E, Fallon K, Oosterbaan C, Page P, Hadhazy M, Quattrocelli M, Barefield D and McNally E: A gene-edited mouse model of limb-girdle muscular dystrophy $2 \mathrm{C}$ for testing exon skipping. Dis Models Mech 13: dmm040832, 2019.

115. Aartsma-Rus A and van Putten M: The use of genetically humanized animal models for personalized medicine approaches. Dis Model Mech 13: dmm041673, 2019

116. Sevastre B, Blidaru A, Sárpataki O, Marcus I and Coman C: Retrospective assessment of animals experimentation projects in Romania-a critical analysis of non-technical summaries. Bull UASVM Vet Med 75: 190-194, 2018

117. Collins CA and Morgan JE: Duchenne's muscular dystrophy: Animal models used to investigate pathogenesis and develop therapeutic strategies. Int J Exp Pathol 84: 165-172, 2003. International (CC BY-NC-ND 4.0) License. 